\title{
A Laboratory Study into a Novel, Retrofittable Rainwater Harvesting System
}

\author{
Peter Melville-Shreeve $^{{ }^{*}}$, Chris Horstman $^{2}$, Sarah Ward ${ }^{1}$, Fayyaz Ali Memon ${ }^{1}$ \\ and David Butler ${ }^{1}$ \\ ${ }^{1}$ University of Exeter, Centre for Water Systems, United Kingdom. \\ ${ }^{2}$ The University of Arizona, College of Engineering, United States.
}

\begin{abstract}
Authors' contributions
This work was carried out in collaboration between the authors. Author PMS designed and completed the laboratory studies with support from author $\mathrm{CH}$. Authors $\mathrm{SW}$ and DB supervised the study, supported method development and helped author PMS write up the outputs. All authors read and approved the final manuscript.
\end{abstract}

Article Information

DOI: 10.9734/BJECC/2016/23724

Original Research Article

Received $18^{\text {th }}$ December 2015 Accepted 22 $2^{\text {nd }}$ January 2016 Published $13^{\text {th }}$ July 2016

\section{ABSTRACT}

Aims: To establish the system characteristics of a novel rainwater harvesting system.

Study Design: A laboratory test rig was used to assess the selected technology.

Place and Duration of Study: University of Exeter, Centre for Water Systems between June 2014 and May 2015.

Methodology: Previous research has identified that systems should have: 1) reduced capital costs, 2) reduced operational costs and 3) increased ease of retrofitting. To investigate the system's ability to address these requirements, two full-scale laboratory test rigs have been used to assess flow and power consumption characteristics under a range of installation scenarios.

Results: The system was identified to have a mean power consumption of $0.12 \mathrm{kWh} / \mathrm{m}^{3}$ during a one hour pump test. Electrical costs were found to increase when the power consumption of the $11 \mathrm{~W}$ control board was taken into account.

Conclusion: Subject to reduction of the standby power consumption of the controller, the novel RWH system assessed in this study has potential to provide non-potable water supplies to households in the UK at a lower power consumption rate than existing water supply systems identified in the literature.

Keywords: Alternative water supply systems; rainwater harvesting; retrofit SuDS; water demand management. 


\section{INTRODUCTION}

Rainwater harvesting (RWH) in the UK is an under-utilised technology that is often cited as a simple, low cost solution to a wide number of pressures associated with our water resources. For example, Kellagher [1] set out a range of benefits that could potentially align to see RWH become a technology that will support increased resilience to a range of potential threats such as drought, increasing energy costs and stormwater flooding. Defining and quantifying these wider benefits will become increasingly important as the magnitude and frequency of these threats increases as a result of climate change in the years ahead [2]. Internationally, RWH has been successfully retrofitted in Australia and Germany, yet it remains difficult to cost-effectively retrofit at residential properties within the UK [3-6]. At a household scale, the UK RWH market remains relatively immature and is focussed on new-build installations, although some retro-fitting has taken place [7].

RWH systems are installed in buildings to allow rainwater from roof surfaces to be collected and stored for non-potable water applications. In developed countries, the prevalence of professionally installed RWH systems has grown in recent years [4]. This is particularly true in regions of the world that have experienced drought conditions such as Melbourne, Australia, where the installation of 25,000 rainwater tanks has been subsidised by government incentive schemes since 2003 [8]. In Europe, a recent study estimates that $50,000 \mathrm{RWH}$ systems are installed each year in Germany [5].

In the UK, RWH systems are typically designed to comply with specifications and water quality standards set out in the British Standard [9], with non-potable water use including; "WC flushing, laundry use and garden watering". Unlike in Australia, where RWH tanks can frequently be located at ground level, the UK's freezing temperatures during winter months requires RWH systems to be designed with tanks below ground level $[9,10]$. Roebuck et al. [11] illustrated that these RWH systems are expensive to install and Melville-Shreeve et al. [12] identified alternative configurations that can potentially be installed at a lower cost. Building on those studies, the research presented in this paper has been undertaken collaboratively with the patent holders of an innovative system marketed under the name FlushRain [13]. The research focuses on initial results from the first phase of the project in which the FlushRain RWH (FRWH) system was trialled in a laboratory setting to enable its basic performance characteristics to be assessed.

\section{MATERIALS: THE FLUSHRAIN RWH SYSTEM}

The FRWH system is described by UK patent GB2449534 and is illustrated in Fig. 1. The system uses downpipe chambers, flexible hoses and a suction pump located within the loft space of a house to draw water from the downpipes into a loft tank during a rainfall-runoff event. Harvested rainwater can be supplied under gravity to non-potable end uses throughout the property. The system has been developed to address three design objectives that are perceived to be weakly addressed by existing RWH products (FlushRain Ltd, personal communication, 29 May 2015); "1) The capital cost should not exceed $£ 1,000 ; 2$ ) Electricity costs should be less than alternative water resources including traditional RWH systems and municipal water supplies; 3) The system is intended to be easily retrofitted within a single day by two installers".

Appraisal against the first two design objectives was undertaken through the construction of a FRWH system in the University of Exeter's Laboratories. Further work to appraise the third objective is underway, but not considered in this paper. Details of the system installed are described below.

\subsection{Downpipe Collection Chambers}

The downpipe collection chambers allow approximately 2 litres of rainwater to pool in the existing downpipe, ready to be pumped into the loft tanks. The downpipe is capped causing it to surcharge up to the level of an overspill weir. Water spilling from this weir is recaptured in the outer chamber and returned to the lower section of the downpipe as illustrated in Fig. 2.

\subsection{Debris Filter and Non-return Valve}

A debris filter is located at the inlet to each suction hose at the base of the collection chambers. It is intended to prevent leaf litter from reaching the pump and storage tank using a two stage screen with $4 \mathrm{~mm}$ holes and a fine mesh. It is designed to be self-cleaning, as rainwater is 
able to wash through the chamber at the beginning of each storm to remove debris.

\subsection{Water Level Sensors}

A capacitance based float switch is installed at the top of the downpipe chamber. The switch senses when it is submerged in water and closes a circuit on the control board. One switch is included at the top water level in each downpipe collector. Another sensor in the top of the storage tank is programmed to prevent the pump from activating when the tank is full.

\subsection{Collection Hoses}

The system uses flexible $15 \mathrm{~mm}$ diameter hoses to collect water from each chamber. These are fed up through the downpipe and passed into the property through the roof fascia boards. The

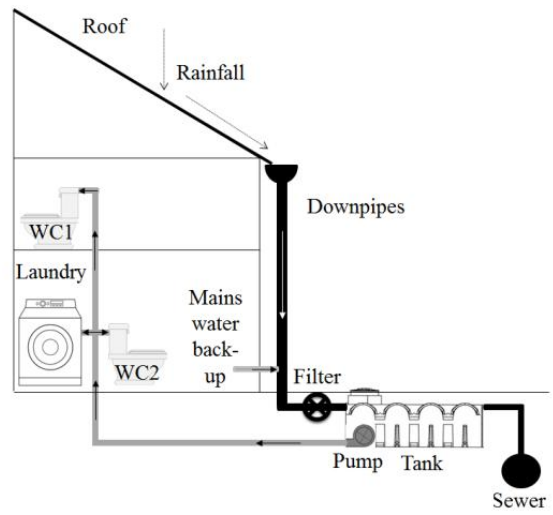

hoses are laid through the loft space and attached to the pump.

\subsection{Rainwater Pump}

A diaphragm pump (The Whale Gulper 220 DC) with a specified maximum suction head of $3 \mathrm{~m}$ is installed in the loft. The pump is able to selfprime (i.e. can remove the air from the suction lines) and is unlikely to experience major issues associated with short periods of dry running. The pump is controlled by a circuit board connected to the water level sensors.

\subsection{Tanks}

A free-flowing outlet from the pump enters the top of the storage tanks via a suspended foam filter gauze which can be washed for reuse.

Fig. 1. Illustration of a traditional RWH system (left) and a FlushRain RWH system (right)
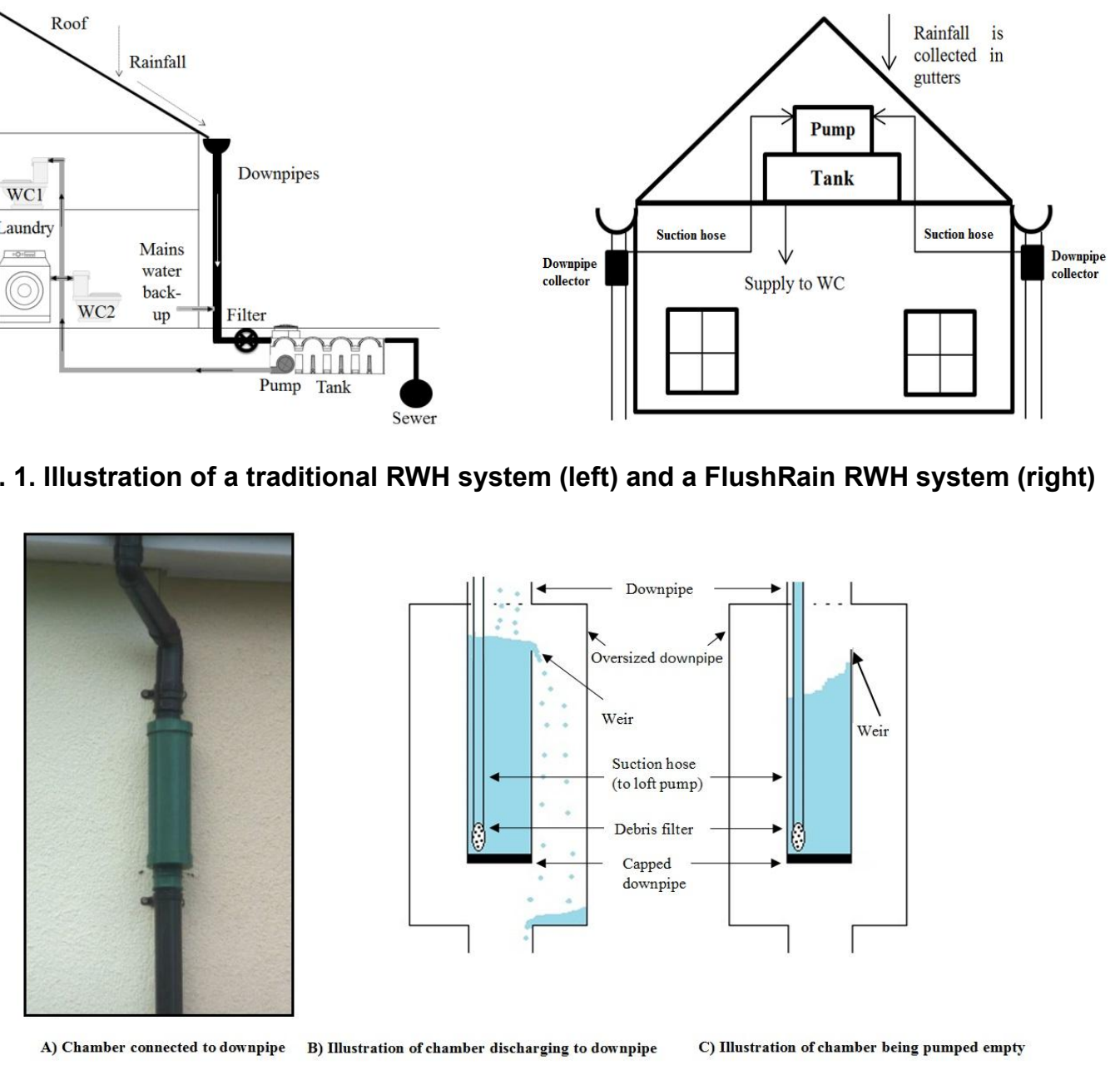

Fig. 2. Illustration of the downpipe collection chambers 
Standard WRAS approved [14] cold water loft tanks are used to store the water in the loft. For the purposes of this study, a tank with approximately 230 litres of storage was utilised, although in real-world installations one or more could be connected subject to the structural loading capacity and space available in the loft. Suitable insulation blankets and pipe lagging are included on the tanks and pipework. Finally, a mains water top-up is installed to allow a shallow level of water to be maintained in the tanks when no rain is available. This is designed to ensure the non-potable supply pipework is always fed with water, even when rainwater has been exhausted.

\subsection{System Function}

During a rainfall-runoff event, runoff fills both collectors and their water level sensors are activated. A ten second delay allows debris collected in the chamber (i.e. leaf litter) to wash through the weir into the overflow pipe. Residual sediment must be cleaned out during maintenance of the system. Following the delay, the pump is activated and the suction hoses feed runoff via the filter into the storage tank. During low intensity rainfall-runoff events, the pump empties the runoff from the collectors and the float switches recognise they are no-longer full. The pump is programmed to continue running for 15 seconds in order to remove excess runoff from the downpipe collectors at the end of a rainfall-runoff event. Once further runoff has accumulated in the collectors, the system restarts. After heavy rain, the tank may become full and the pump stops when the top water level sensor is activated. An overflow from the loft tank provides a failsafe discharge point in case this sensor fails. Harvested rainwater stored in the loft is then plumbed directly to WCs and washing machines for reuse.

\section{METHODS}

Two laboratory test rigs (Figs. 3 and 4) using recirculated potable water were used to answer the following research questions:

RQ1) Can the FRWH system function with either one or two downpipes connected?

RQ2) How does the system function when static head is increased?

RQ3) What is the electricity consumption of the system in comparison with alternative RWH systems and municipal supplies?

\subsection{Test Rig 1: Assessing Head-flow Relationships}

A laboratory test rig was constructed to mimic the pipe arrangements of the FRWH system as illustrated in Fig. 3. The arrangement allowed for the pump to be mounted at a range of static heads $(0.26 \mathrm{~m}$ to $2.56 \mathrm{~m})$ above a source water tank. At each mounting level, the system was turned on and allowed to prime with water. The flow from the pump was then routed into a tank located upon a set of scales. The mass collected in the tank over a period of time was used to establish the pump's flow rate. The equipment was used to establish a maximum static head (i.e. vertical distance) between the pump and the collection chambers, above which the pump is unable to draw water into the tank (i.e. elevation and friction head exceeds suction head). The horizontal pipe lengths were kept fixed throughout the tests using $4.85 \mathrm{~m}$ of $15 \mathrm{~mm}$ hose. As the static head was increased, an additional length of $22 \mathrm{~mm}$ pipe was added to the system to allow the pump to be connected at the increased height above the water tank. Thus the measurement of static heads represents a realworld installation in which pipe lengths would increase as the vertical distance between collection chamber and the pump increases.

For Test Rig 1, tests were repeated three times at each static head and mean results recorded. Testing was undertaken by altering the following variables:

1) The number of pipes connected to the pump (either 1 or 2 were connected);

2) The static head was increased in five steps from $0.26 \mathrm{~m}$ to $2.56 \mathrm{~m}$ in order for a head-flow curve to be derived.

\subsection{Test Rig 2 - Full Scale Test Installation to Establish Electrical Consumption}

Test Rig 2 comprised an installation in a section of full scale roof as illustrated in Fig. 4. The FRWH system was installed with $2 \times 4.85 \mathrm{~m}$ lengths of $15 \mathrm{~mm}$ diameter pushfit pipework laid within the roof space. Pumped water was routed into a measuring vessel in order for flow rates to be monitored during testing. A control valve was used to deliver water to the gutter at a rate which exceeded the pump's maximum flow rate. The second collection hose was placed in a constanthead tank adjacent to the downpipe. This 
allowed both collectors to have access to an unlimited incoming flow throughout the tests.

Test Rig 2 was used to monitor the electrical usage of the system under constant incoming flow conditions from two collection hoses. Electricity usage was recorded using an EL-USBACT data logger in combination with a current clamp. The AC current at the pump's control board was monitored using the current clamp. The data logger required an assumed voltage to be set and following testing an average value of $230 \mathrm{~V}$ was used. The logger was then able to record wattage of the system at a $0.25 \mathrm{~s}$ resolution. For the purposes of identifying the energy usage, the pump was switched on and the flow routed into a collection vessel with a known volume. A stopwatch was used to record the time taken to fill the vessel. In each test this was repeated 3 times and the mean time to fill the vessel was used to establish a pump flow rate. The pump was then allowed to run for an hour and its electrical usage monitored. This data was used to calculate the average electrical consumption required to collect $1 \mathrm{~m}^{3}$ under optimal (pump permanently on) running conditions. These tests were then repeated with a single collection hose attached to the pump. Errors in the data collection protocols are considered in a supplementary annex available from the authors on request.

The power consumption associated with suboptimal pump running was also investigated. The process of pump on-off switching was monitored to establish if turning the pumps on and off caused higher electricity usage per unit of water pumped. In order to assess this factor, the pumping system was switched on and off rapidly to identify any spikes in the electricity required to start the pump when the system activates.

\section{RESULTS AND DISCUSSION}

The results from the laboratory testing are discussed in the following sections, along with other implications for the FRWHS and further research requirements.

\subsection{Test Rig 1 - Assessing Head-flow Relationships}

Results from the tests conducted on Test Rig 1 were used to establish the head-flow relationships that might be expected in a realworld installation. The results are illustrated in Fig. 5.

Minimum and maximum values for each static head tested did not vary by more than +/$0.11 / \mathrm{s}$ from the mean value. Although a small sample set was collected, the standard deviation did not exceed 0.12. The data illustrates that the FRWH system can operate with either one or two collection chambers connected, which results in an answer of 'yes' to RQ1.

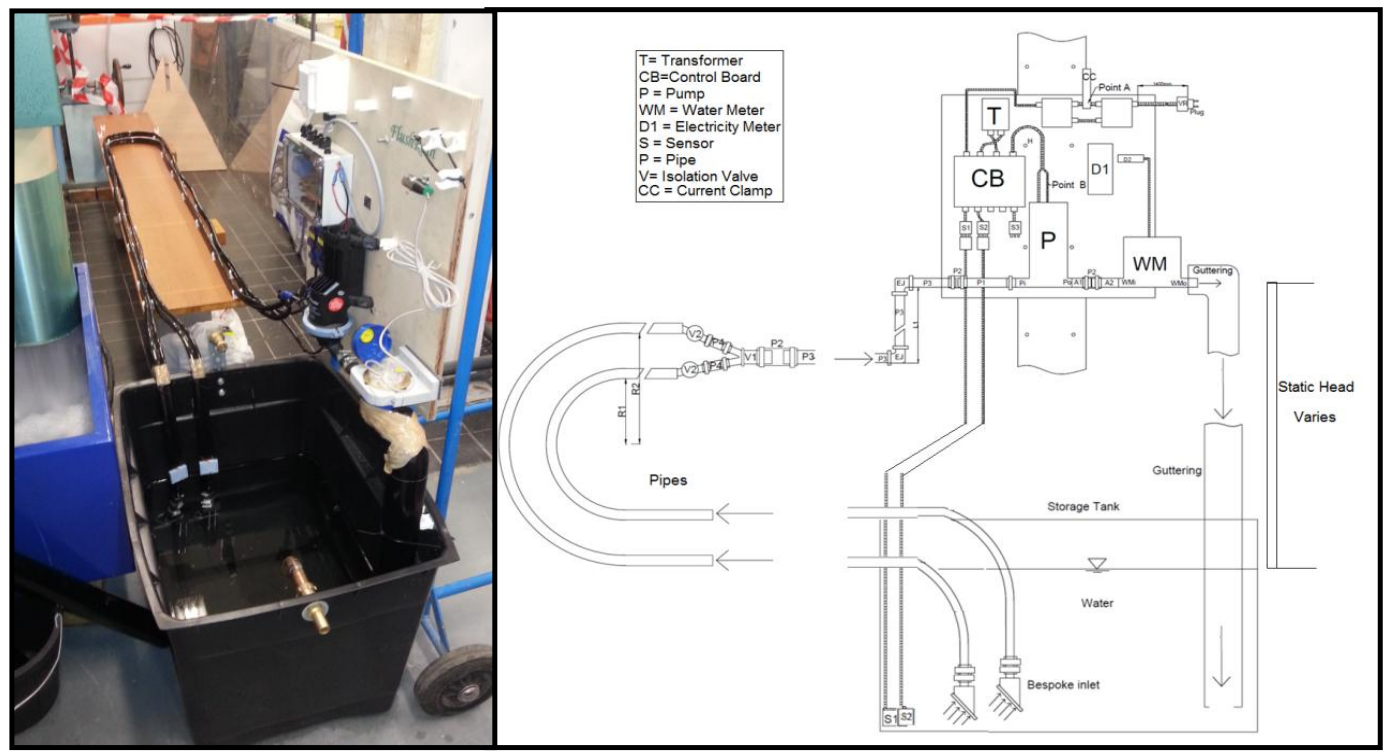

Fig. 3. Photo and layout drawing of Test Rig 1 


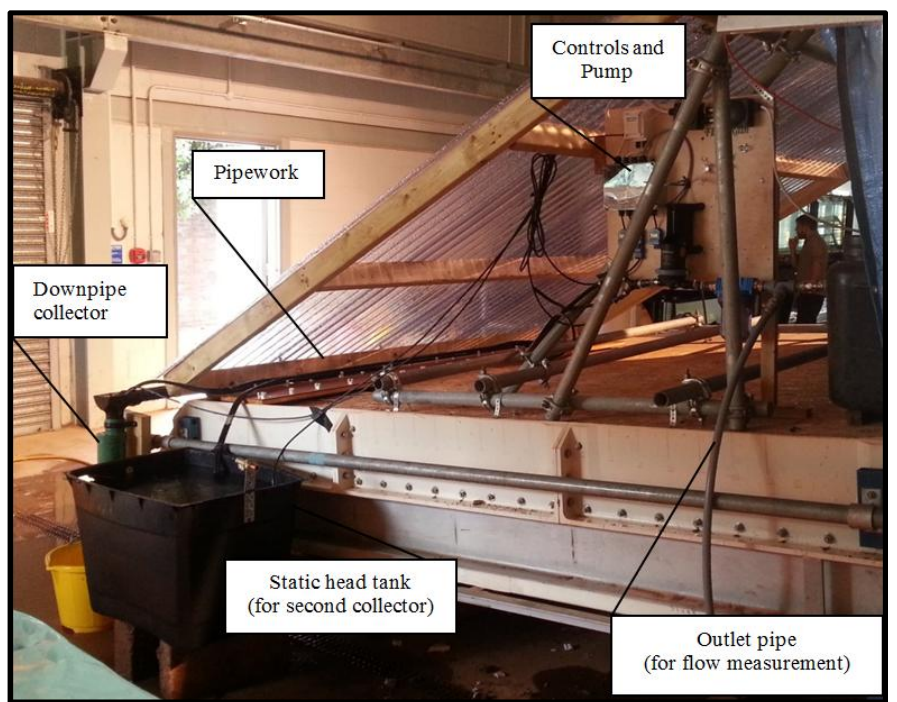

Fig. 4. Image of Test Rig 2

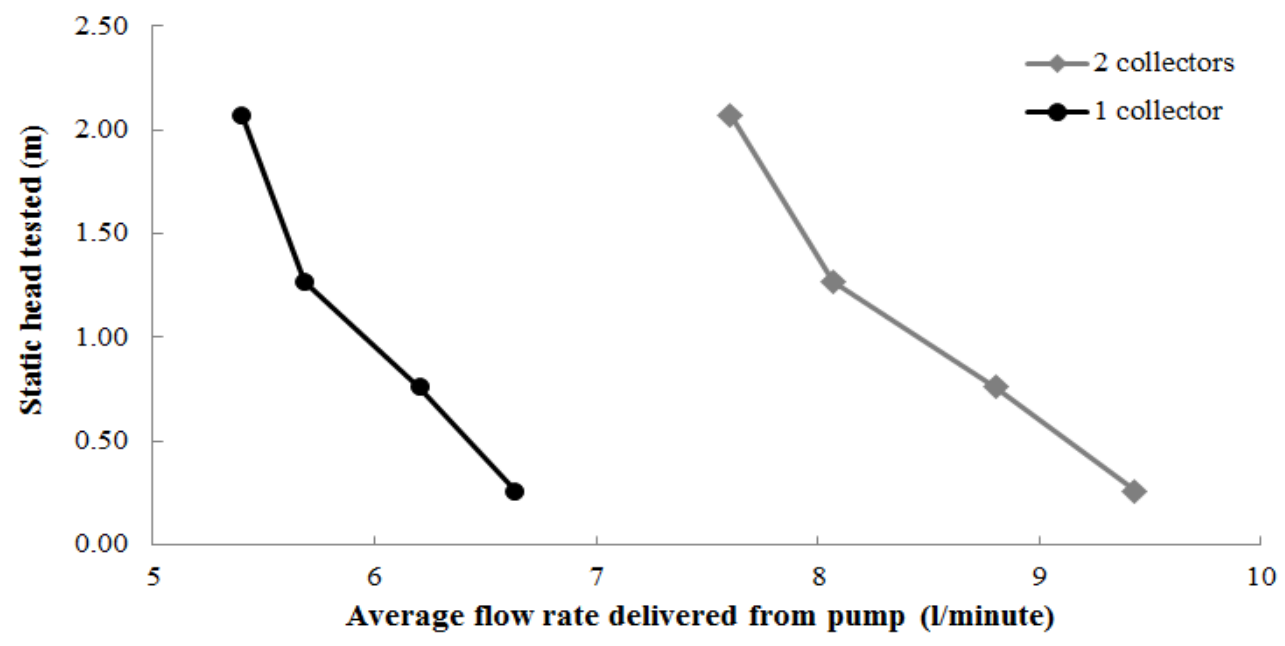

Fig. 5. Head-flow relationships for the FRWH system as identified from Test Rig 1

As might be expected, the rate of flow decreases as the static head increases, and the system is able to deliver a greater volume of flow when pipe friction is reduced (i.e. both $15 \mathrm{~mm}$ pipes are connected). This illustrates that the pump is able to function more efficiently when two downpipe collectors are attached (i.e. front and back of house) rather than having a single pipe connected to a single pump. Flow rates of $>9 \mathrm{l} / \mathrm{m}$ were observed for the lowest static head when two pipes were connected. In contrast, the lowest flow rate recorded was $5.41 / \mathrm{m}$ for a single collector at $2.08 \mathrm{~m}$ static head (i.e. a vertical distance of $2.08 \mathrm{~m}$ between the inlet to the pump and the water being lifted). For both one and two collectors, the system failed (i.e. the pump only drew air into the tanks and was unable to selfprime) when a static head of $2.56 \mathrm{~m}$ was tested. As well as answering RQ2, this also suggests that installations with collectors that are installed more than $2.08 \mathrm{~m}$ below the pump inlet would not be advisable in a real-world setting.

The FRWH system's pump capacity was shown to exceed $7.61 / \mathrm{m}$ when collecting from two downpipes. This equates to capturing rainfall of $10.1 \mathrm{~mm} /$ hour (when collecting from a typical house with a $50 \mathrm{~m}^{2}$ roof at a runoff coefficient of $0.9)$. For comparison, rainfall intensities of $50 \mathrm{~mm} /$ hour over a 10 minute duration are calculated to have a return period of 1 in 4 years for Exeter, UK [15]. Designers utilising the FRWH 
system may choose to install multiple collectors and pumps where roof runoff is anticipated to frequently exceed the system's collection capacity.

\subsection{Test Rig 2 - Electricity Usage: Constant Flow through Pump}

The system was run with two pipes connected to the pump for a one hour window and the resulting electricity consumption data is illustrated in Fig. 6. The data shows the pump's power usage is constantly fluctuating between approximately 50-100W.

The average $\mathrm{kW}$ usage recorded was $0.072 \mathrm{~kW}$ $( \pm 5.3 \%)$. Scaled to an hour of usage this equates to $0.072 \mathrm{kWh}( \pm 5.3 \%)$. Records of the pumped flow during the one hour window (Fig. 6) illustrate an average flow rate of $9.6 \mathrm{l} / \mathrm{m}$.

Repeating the above test with a single collector running for one hour yielded power usage as illustrated in Fig. 7. As with the two collector scenario, the pump operates at a power usage of approximately $50-100 \mathrm{~W}$.
The results obtained are consistent with the findings of a number of other tests conducted using Test rig 2 which verified that the pump runs at a consistent electrical consumption rate, within a band of approximately $50-100 \mathrm{~W}$, regardless of the static head, friction head or flow rate. The pump's consistency allows relatively accurate estimations to be made of the electricity required to collect rainfall-runoff using the FRWH system. Taking an average electricity usage of the pump running over one hour as $0.072 \mathrm{kWh}( \pm 5.3 \%)$ and a recorded flow rate of $9.61 / \mathrm{m}( \pm 3.8 \%)$ it is possible to assert, in relation to $R Q 3$, that the energy usage for provision of $1 \mathrm{~m}^{3}$ of water equates to $0.124 \mathrm{kWh}( \pm 9.5 \%)$, costing $1.68 \mathrm{p}$ at $13.52 \mathrm{p} / \mathrm{kWh}$ [16]. This figure increases to $0.139 \mathrm{kWh}$ for a flow of $7.6 \mathrm{l} / \mathrm{m}( \pm 3.53 \%)$ giving $1.88 \mathrm{p} / \mathrm{m}^{3}$ in the event that a single collector is operating. This compares to South West Water's [17] municipal water charge of $£ 2.05 / \mathrm{m}^{3}$, generating a potential saving of $£ 2.03 / \mathrm{m}^{3}$ collected. However, it is unreasonable to assume that the pumping regime would be "on" for long periods of time. In practice, rainfall-runoff events would cause the pump to switch on and off as the collection chambers filled and were pumped empty.

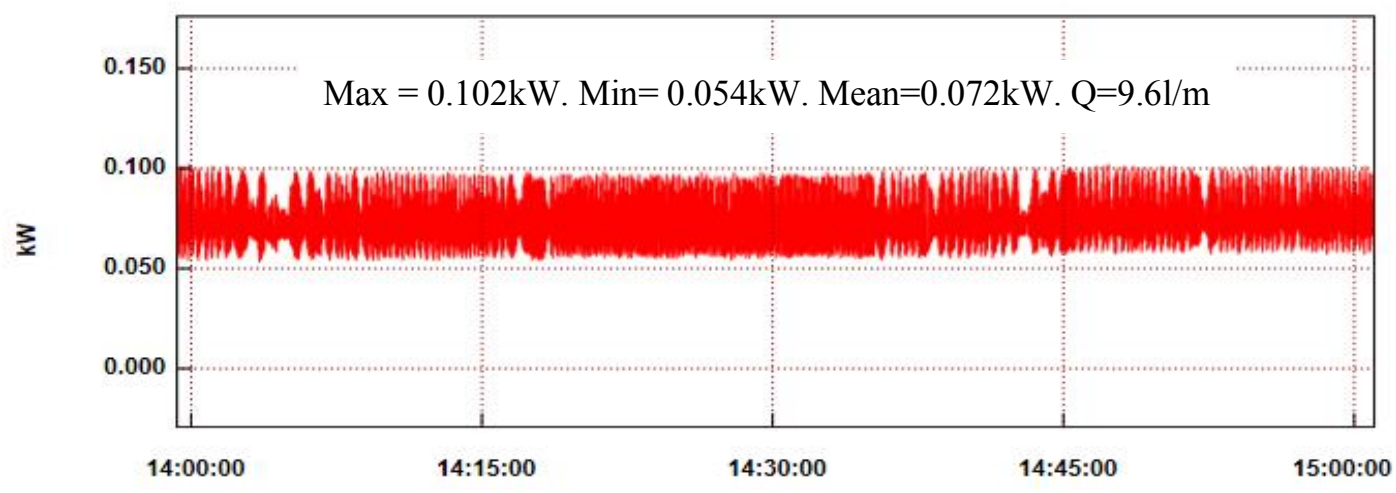

Fig. 6. Power usage at $0.25 \mathrm{~s}$ resolution for 2 collectors pumping for 1 hour

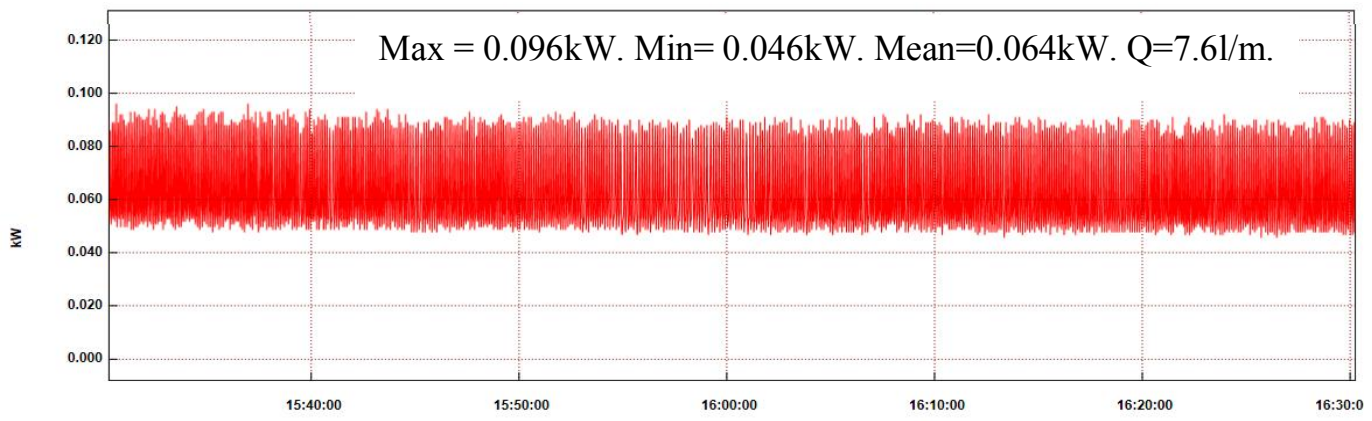

Fig. 7. Power usage at a $\mathbf{0 . 2 5 s}$ resolution for 1 collector pumping for 1 hour 


\subsection{Electricity Usage: Pump Switching On/Off}

The system was allowed to run for a number of test windows with the pumps turned on and off by artificially removing the water level sensors from the water. Each time the pump activated, the switch was removed. When the pump stopped the switch was reintroduced to the water. A 20 minute window of this data is illustrated in the power curve in Fig. 8. With flows starting and stopping as the pump is switched on and off, the average flow rate was less than the 'pump on' scenario and averaged $6.71 / \mathrm{m}( \pm 3.6 \%)$. It is evident from Fig. 8 that even when the pumps are switching on and off frequently, the mean power required does not exhibit spikes in power consumption. It is possible that power spikes are more frequently experienced in centrifugal pumps which are used in most existing RWH systems [18]. Fig. 8 also illustrates that a standby power of $11 \mathrm{~W}$ was recorded when the pump was off.

The pump-switching tests illustrate that $6.71 / \mathrm{min}$ can be delivered at a cost of $0.049 \mathrm{~kW}$. This equates to a cost of $1.65 \mathrm{p} / \mathrm{m}^{3}$, less than the cost when the pump is permanently on. In contrast to the expected outcome, this implies that pump switching on and off does not increase the overall cost of water collection.

\subsection{Comparison with Literature on Electricity Consumption of RWH Systems}

The electricity consumption for the pump used in the novel RWH system assessed in this paper $\left(0.12 \mathrm{kWh} / \mathrm{m}^{3}\right)$ compared favourably to electricity use data from existing RWH systems $\left(0.54 \mathrm{kWh} / \mathrm{m}^{3}\right)$ monitored by Ward et al. [18] which also notes that UK municipal water supplies use around $0.60 \mathrm{kWh} / \mathrm{m}^{3}$. This can be attributed to; 1) the low power consumption for the pump ( 50-100W), the low operating head, and the lack of increased power consumption during pump start-up. A further comparison was drawn against the existing market leader for household RWH which claims a value of $0.68 \mathrm{kWh} / \mathrm{m}^{3}$ for its RainDirector system [19]. Internationally, Vieira et al. [20] reviewed empirical data from $10 \mathrm{RWH}$ studies and identified a median power usage of $1.40 \mathrm{kWh} / \mathrm{m}^{3}$. For contrast this study also offers a figure for global desalination of water at $3.60 \mathrm{kWh} / \mathrm{m}^{3}$.

The annual electricity costs for pumping were projected to be very low at less than $£ 1$ per year (assuming a nominal $30 \mathrm{~m}^{3}$ usage consuming $3.72 \mathrm{kWh}$ at $13.52 \mathrm{p} / \mathrm{kWh}$ ). In comparison, water rates for the highest-charging water company (SWW, 2014) would cost a customer $£ 61.50$ based on a rate of $£ 2.05 / \mathrm{m}^{3}$. However, the electronics supporting the system were found to have a mean standby power consumption of $11 \mathrm{~W}$ (Fig. 8). A total standby energy cost of $96.36 \mathrm{kWh} /$ year was projected at a cost of $£ 13.41$. Assuming a $30 \mathrm{~m}^{3}$ per annum usage, a total electricity usage of $3.34 \mathrm{kWh} / \mathrm{m}^{3}$ was projected from the results, five times higher than the operational power consumption of average municipal supplies. A reduction in the standby power consumption of the FRWH system will be necessary if the system is to achieve electrical usage that is comparable to existing water supply infrastructure. If the standby power consumption can be eliminated then the system is likely to achieve lower electricity use per $\mathrm{m}^{3}$ than existing RWH systems. Real-world pilot trials are planned in order to establish the validity of the assumptions and calculations set out in this paper and to enable empirical evidence to be collected on the capital and operational costs associated with this novel RWH technology.

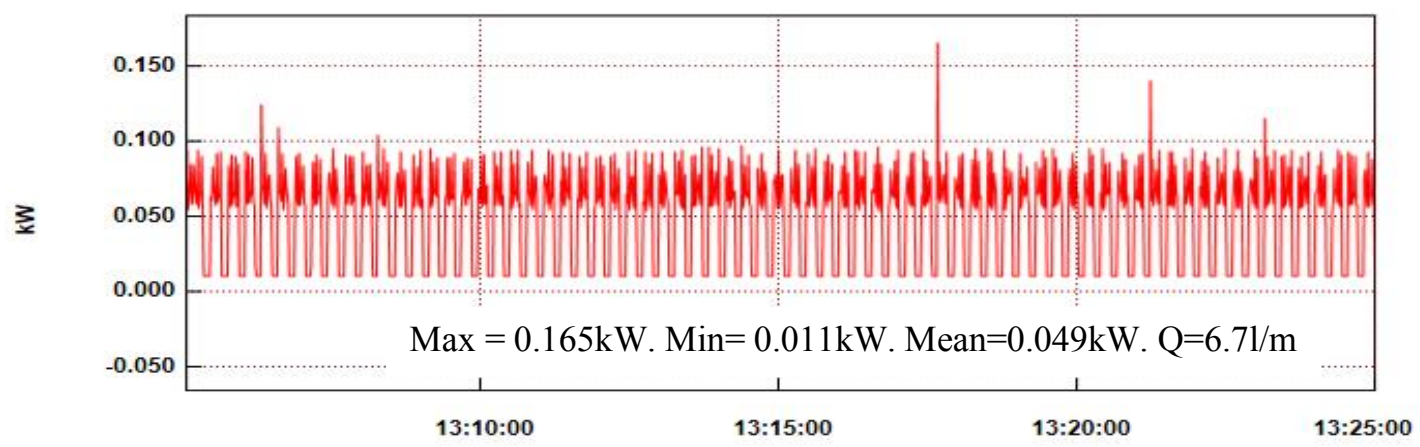

Fig. 8. System power usage at a $\mathbf{0 . 2 5 s}$ resolution for 2 collectors pumping for 20 minutes with maximum pump switching 


\section{CONCLUSIONS}

The following conclusions can be drawn;

1) The FlushRain RWH system can function with one or two pipe collectors connected although a greater volume of rainfall-runoff can be collected when two pipes are connected.

2) Flow rates reduced as the static head was increased. The system failed to operate at a static head of $2.56 \mathrm{~m}$ and consequently, it is not recommended for installation where the static head significantly exceeds $2.00 \mathrm{~m}$.

3) Results showed the electrical consumption of the pump to be $0.12 \mathrm{kWh} / \mathrm{m}^{3}$ or 3.72 $\mathrm{kWh} /$ year assuming $30 \mathrm{~m}^{3}$ of harvested water is used. This was found to be significantly lower than other consumption data in literature relating to existing $\mathrm{RWH}$ technologies, municipal water systems and desalination supplies. However, the control electronics were found to use $11 \mathrm{~W}$ and as they are permanently on this contributes an additional $96.36 \mathrm{kWh} /$ year. The average electricity usage for the system was therefore projected to be greater than municipal supplies at $3.34 \mathrm{kWh} / \mathrm{m}^{3}$. Consequently, reconfiguration of the standby control system will be needed if the system seeks to limit its electrical consumption levels to those documented for existing water supply systems.

\section{ACKNOWLEDGEMENTS}

The study was funded by sponsorship from Severn Trent Water plc and the UK Engineering \& Physical Sciences Research Council through a STREAM Engineering Doctorate.

\section{COMPETING INTERESTS}

The authors of this paper conducted this research on and independent basis on behalf of the University of Exeter at the request of the patent holder for the system. A research contract between FlushRain Itd and University of Exeter Consulting Ltd. was set up to allow the University of Exeter to be remunerated for staff time and laboratory costs associated with the study.

\section{REFERENCES}

1. Kellagher R. Stormwater management using rainwater harvesting: Testing the
Kellagher/Gerolin methodology on a pilot study. HR Wallingford Limited, UK; 2011.

2. Murphy J, Sexton D, Jenkins G, Boorman $\mathrm{P}$, Booth $\mathrm{B}$, Brown $\mathrm{K}$, Clark R, Collins $\mathrm{M}$, Harris G, Kendon L. Met Office hadley centre. UK Climate Projections Science Report: Climate Change Projections; 2009.

3. Burns MJ, Fletcher TD, Duncan HP, Hatt BE, Ladson AR, Walsh CJ. The performance of rainwater tanks for stormwater retention and water supply at the household scale: An empirical study. Hydrological Processes; 2014.

4. Herrmann T, Schmida U. Rainwater utilisation in Germany: Efficiency, dimensioning, hydraulic and environmental aspects. Urban Water. 1999;1:307-316.

5. Parsons D, Goodhew S, Fewkes A, De Wilde $P$. The perceived barriers to the inclusion of rainwater harvesting systems by UK house building companies. Urban Water Journal. 2010;7:257-265.

6. Stewart RA, Sahlin O, Siems R, Talebpour MR, Giurco D. Performance and economics of internally plumber rainwater tanks: An Australian perspective. In: Memon, F.A. and Ward, S. ed. Alternative Water Supply Systems. London: IWA Publishing. 2015;3-21.

7. MTW. Market research Report - Rainwater Harvesting Market 2010. Rainwater Harvesting Market Size \& Review 20042014; SWOT \& PEST Analysis, Product Mix 2004-2014; End User Mix 2004-2014; Market Leaders Profiles \& Key Financials; Market Forecasts to 2014.

8. Wang $\mathrm{CH}$, Blackmore JM. Supply-Demand Risk and Resilience Assessment for Household Rainwater Harvesting in Melbourne, Australia. Water Resources Management. 2012;26:4381-4396.

9. British Standards Institution (BSI). BS 8515:2009+A1:2013 Rainwater harvesting systems - Code of practice. BSI, London; 2013.

10. Environment Agency. Harvesting rainwater for domestic uses: An information guide. Environment Agency; 2010.

11. Roebuck RM, Oltean-Dumbrava C, Tait S. Whole life cost performance of domestic rainwater harvesting systems in the United Kingdom. Water and Environment Journal. 2011;25(3):355-365.

12. Melville-Shreeve P, Ward S, Butler D. A preliminary sustainability assessment of innovative rainwater harvesting for 
residential properties in the UK. Journal of Southeast University. 2014;30(2):135-142.

13. FlushRain. Roof Located Rain Water Harvesting; 2015.

Accessed 15 May 2015. Available: http://www.flushrain.co.uk

14. WRAS. What is a WRAS Approval? 2015. Accessed 29 May 2015.

Available:https://www.wras.co.uk/approval s/what is a wras approval/

15. The Institute of Plumbing. Plumbing Engineering Services Design Guide; 1989.

16. Energy Saving Trust (EST). Energy Saving Trust. Our Calculations; 2014.

Accessed 5 August 2014.

Available:http://www.energysavingtrust.org uk

17. South West Water (SWW); 2014. Charges Scheme 2014-2015.
18. Ward S, Butler D, Memon FA. Benchmarking energy consumption and $\mathrm{CO} 2$ emissions from rainwater-harvesting systems: An improved method by proxy. Water and Environment Journal. 2012;26: 184-190.

19. Rainwater Harvesting Itd. (RWH Itd.) Rainwater Harvesting: Reduced use of electricity by the HydroForce ${ }^{\circledR}$ pump and smart header tank; 2013.

Accessed 27 May 2015.

Available: http://www.rainwaterharvesting.c o.uk/downloads/rwh white paper raindire ctor electricity use.pdf

20. Vieira AS, Beal CD, Ghisi E, Stewart RA. Energy intensity of rainwater harvesting systems. Renewable and Sustainable Energy Reviews. 2014;34:225-242.

(C) 2016 Melville-Shreeve et al.; This is an Open Access article distributed under the terms of the Creative Commons Attribution License (http://creativecommons.org/licenses/by/4.0), which permits unrestricted use, distribution, and reproduction in any medium, provided the original work is properly cited. 